Bangladesh Journal of Anatomy July 2012, Vol. 10 No. 2 pp 76-79

\title{
Variation in the Arrangement of Structures at Hilum of Human Kidney
}

\author{
SM Nurul Hassan ${ }^{1}$, Mansur Khali'², Mohsin Khali ${ }^{3}$
}

\begin{abstract}
Context: There is a variation in the arrangement of structures at hilum which may create problem for the surgeon during dissection of hilum of kidney. Moreover, developmental anomalies like, constriction at pelviureteric region, double renal pelvis, accessory renal arteries etc are not uncommon. So, adequate anatomical knowledge of kidney specially at hilum is required for successful surgery of this reason.
\end{abstract}

Objective: To study the variation in the arrangement of renal vessels and renal pelvis at hilum.

Study design: Descriptive type.

Place and period: Department of Anatomy, Mymensingh Medical College, Mymensingh, Bangladesh from January 2004 to June 2005.

Materials and methods: A total of 100 fresh human kidneys of both sexes and sides were collected from the morgue of Mymensingh Medical College at postmortem. The selected cases were between 5 to 60 years of age. The samples were preserved to observe the variations in the arrangement of main structures at hilum of kidneys regardless of age groups.

Results: When hilum of the kidneys viewed before backwards, anteriorly and at the middle, there was $1 \%$ variation in the arrangement of renal vessels but posteriorly renal pelvis was found in variably and it was double in $2 \%$ of kidneys. Posterior division of renal artery was present behind the renal pelvis in $12 \%$ of kidneys.

Conclusion: Variation in the arrangement of structures at hilum was observed in $1 \%$ of kidneys.

Keywords: Kidney, Hilum.

\section{Introduction}

Human kidneys are paired, situated one on each side of the vertebral column at the level of T12 to L3 vertebrae $^{1}$. In average the normal kidney measures $11 \times 6 \times 3 \mathrm{~cm}^{2}$. Measurements made with ultrasound are generally less than those made by radiography ${ }^{3}$. In kidney, hilum is the middle concavity of the medial border through which renal vessels, lymph vessels, nerve plexus and renal pelvis pass and it communicates with renal sinus ${ }^{4}$. Anteriorly faced hilum rotates $90^{\circ} \mathrm{m}$ edially when it ascends from pelvis ${ }^{5,6}$. It can lie laterally, leading to an unusual configuration on excretory urography ${ }^{7}$. Hilum lies

1. Associate Professor \& Head, Department of Anatomy, Uttara Adhunik Medical College, Dhaka.

2. Professor \& Head, Department of Anatomy, Shahid Syed Nazrul Islam Medical College, Kishorganj.

3. Professor \& Head, Department of Anatomy, Mymensingh Medical College, Mymensingh.

Correspondence : Dr. SM Nurul Hassan about $5 \mathrm{~cm}$ away from the mid line, its upper pole lies $2.5 \mathrm{~cm}$ and lower pole $7.5 \mathrm{~cm}$ away from the midline ${ }^{6,8,9}$. Main structures passing through the hilum from before backwards are renal vein, renal artery and renal pelvis $4,6,8,9$. Usually one branch of renal artery and a corresponding tributary of renal vein may pass behind the renal pelvis ${ }^{4,6,9,10}$. About two thirds of the population, each kidney has a single renal artery ${ }^{11}$ and it is $70 \%$ of individuals according to Standring et al. ${ }^{4}$ Multiple renal arteries occur in normal kidneys but are more prevalent in congenitally malformed or mal positioned kidneys ${ }^{11}$. Renal artery divides into branches at or near the hilum and the pattern of branching may vary. In sinus, eventually five or six tributaries unite at the hilum to from the single renal vein ${ }^{6}$. The left renal vein may be double, one vein passing posterior, one anterior to the aorta to join the inferior vena cava. Accessory renal arteries, are present in $30 \%$ of 
individuals; either at the hilum or at one of it's poles ${ }^{4}$. The renal pelvis is the funnel shaped commencement of the ureter, is normally the most posterior of the three main structures at the hilum ${ }^{6}$. The extension of renal pelvis is variable. In some individuals, the entire renal pelvis has been found to lie inside the sinus of the kidney ${ }^{4}$. Duplication of the ureter results from early splitting of the ureteric bud. Splitting may be partial or complete; as a consequence, double renal pelvis partly or completely being formed ${ }^{12}$. Capacity of the pelvis is about 5-7 $\mathrm{ml}^{6,9}$.

Available articles are the evidences that human kidney has been widely studied in different races by various investigators. By studying of hilum of 100 kidneys, it is found that there are considerable changes in the arrangement of main structures. This study shows normal developmental process as well as congenital anomalies $4,6,8,9,12$. Regarding arrangement of structures at hilum of kidney, very few research work has been performed in our country. So this study was intended to evaluate the variation in the arrangement of structures at hilum of kidney collected from Bangladesh.

\section{Materials and Methods}

The present study was performed on 100 kidneys of both sexes and sides in the Department of Anatomy of Mymensingh Medical College. The samples were collected from unclaimed fresh dead bodies that underwent routine postmortem examination in the morgue of the Department of Forensic Medicine, Mymensingh Medical College from January 2004 to June 2005. Kidneys of decomposed bodies and kidneys with gross anatomical anomalies were excluded. The samples preserved in $10 \%$ formol saline were washed to avoid irritation of the eyes and nasal mucosa. Then the samples were taken in metallic tray and the surrounding fat and other unwanted structures were removed smoothly but structures at hilum were kept intact carefully. Then a general study of the relation among the renal vessels and the renal pelvis at the hilum was done and noted.

\section{Results}

In the present study, 100 human kidneys were selected for observation of variation in the arrangement of structures at hilum. The arrangement of main structures at hilum of the kidneys was represented in fig.-1. The individual variations of the main structures at hlum were illustrated in Fig. 2-4. Here, $12 \%$ of kidneys showed posterior division of renal artery behind the renal pelvis.

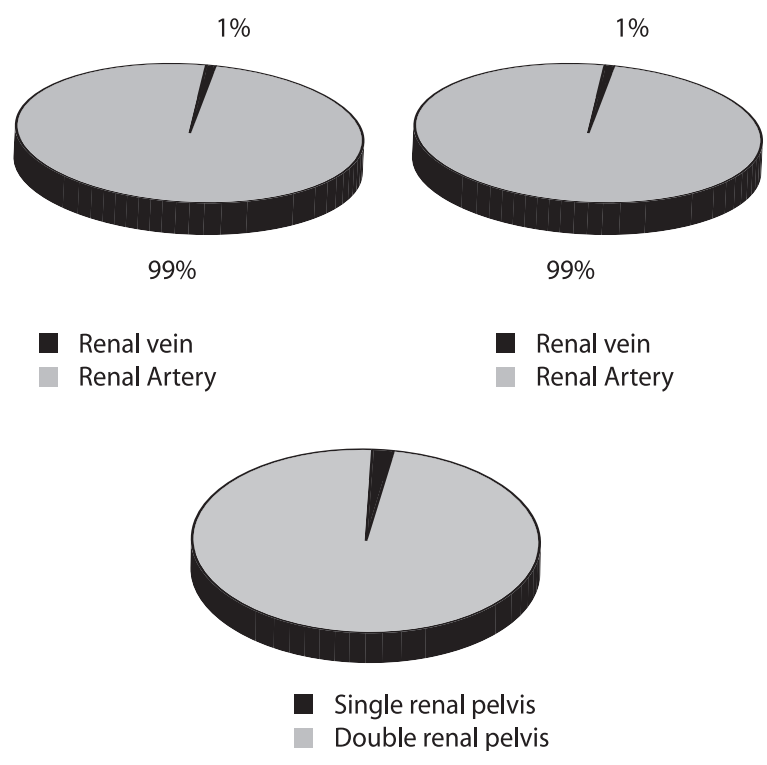

Fig.-1: Arrangment of the structures at hilum

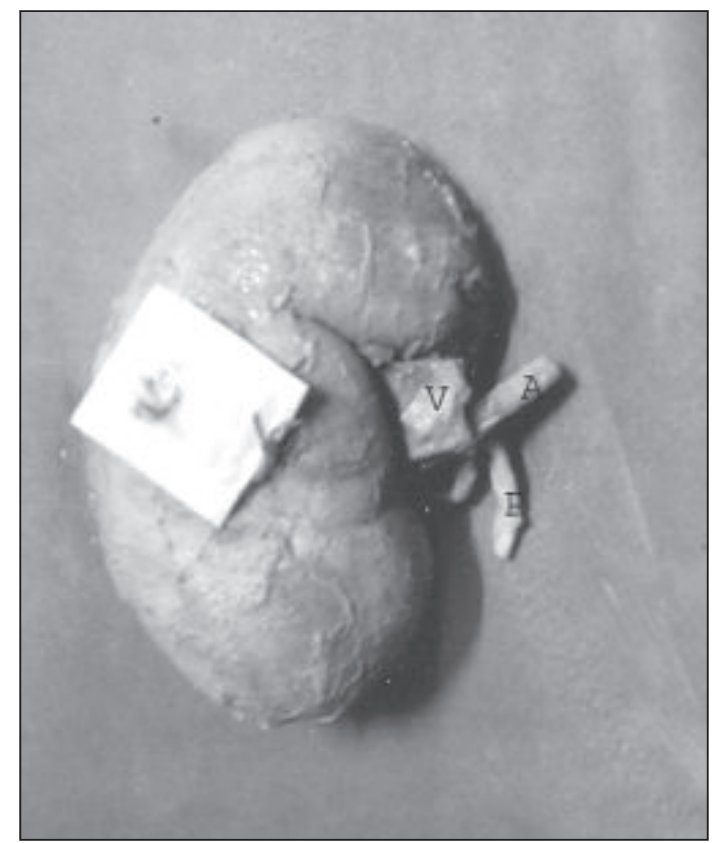

Fig.-2: Showing the typical arrangement of structures at hilum of kidney ( $V=$ Vein, $A=$ Artery, $P=$ Pelvis). 


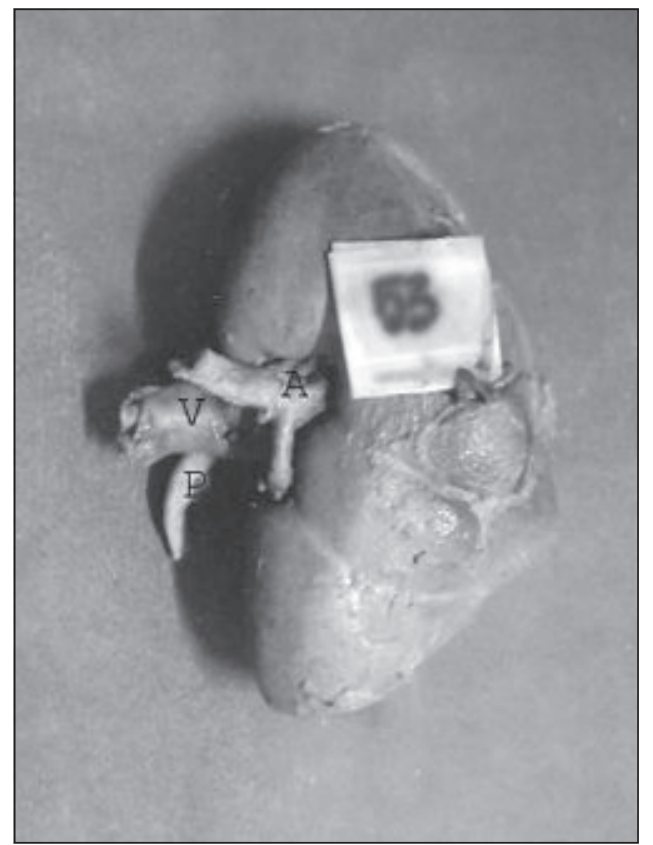

Fig.-3: Showing the renal artery anteriorly $(V=$ Vein, $A=$ Artery, $P=$ Pelvis).

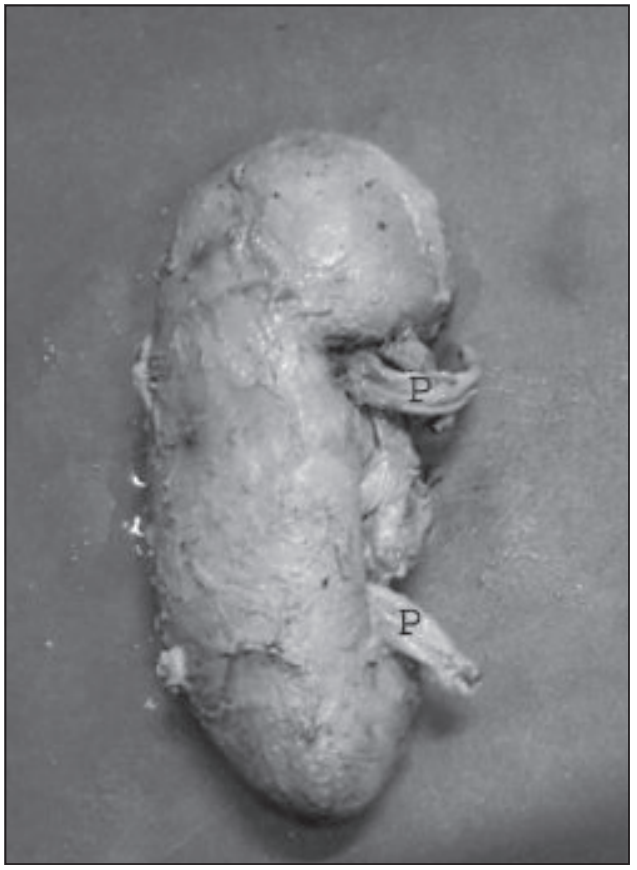

Fig.-4: Showing the double renal pelvis ( $P=$ Pelvis).

\section{Discussion}

In this study, a general investigation at the hilum of kidney was done regardless of age groups. The hilum of 100 kidneys was examined before backwards for renal vessels and renal pelvis to observe their relative position. Among them, renal vein was found anteriorly in $99(99 \%)$ kidneys and only $1(1 \%)$ kidney was found with renal artery anteriorly. At the middle of the hilum, the arrangement of the renal vessels was vice-versa to anterior. Out of 100 kidneys, renal pelvis was observed $100 \%$ posteriorly and $12(12 \%)$ kidneys were found with posterior division of renal artery behind the renal pelvis. In case of $2(2 \%)$ kidneys, the renal pelvis was found to be double in each of them. So, in the present study, the arrangement of the renal vessels and renal pelvis at the hilum is almost $(99 \%-100 \%)$ similar to that of the findings described by Sinntamby 6 , Jakob ${ }^{8}$, Datta ${ }^{9}$, Standring et $\mathrm{al}^{4}{ }^{4}$. A few studies are also available, reporting the existence of multiple renal vessels in normal kidneys which is partially in disagreement with the observations of this study ${ }^{4,11}$.

Regarding the anterior and middle position of the renal vessels very minimum (1\%) variation is observed here. However, there is no difference in the position of renal pelvis which is invariably found posteriorly at the hilum. Occationally, posterior division of renal artery is present behind the renal pelvis.

\section{References}

1. Moore KL, Agur AMR. Essential clinical anatomy. $2^{\text {nd }}$ ed. Baltimore: Lippincott, Williams \& Wilkins; 2002: 180-85.

2. Walsh PC, editor. Campbell's urology (V-1). $8^{\text {th }}$ ed. Philadelphia: Saunders; 2002: 19-35.

3. Palmer PES, editor. Manual of diagnostic ultrasound. $1^{\text {st }}$ ed. USA: World Health Organization; 1995: 154-55.

4. Standrings, Ellis H. Healy JC, Johnson D, William A, editors, Gray's Anatomy. $39^{\text {th }}$ ed. London: Churchill Livingston; 2005: 1271: 1274,1276 .

5. Cochard LR. Netter's atlas of human embryology. $1^{\text {st }}$ ed. USA: Icon Learning System LLL; 2002: 161-65. 
6. Sinnatamby CS. Last's anatomy regional and applied. $11^{\text {th }}$ ed. UK: Churchill Livingstone Elsevier; 2006: 294.

7. Sutton $D$, editor. Textbook of radiology and imaging (V-2). $6^{\text {th }}$ ed. New York: Churchill Livingston; 1998: 1131-33.

8. Jacob S. Atlas of human anatomy. $1^{\text {st }}$ ed. UK: Churchill Livingstone; 2002: 124-25.

9. Datta AK. Essentials of human anatomy (part1). $8^{\text {th }}$ ed. Calcutta: Current Books International; 2008: 294-96.
10. Snell RS. Clinical anatomy. $9^{\text {th }}$ ed. Baltimore: Lippincott Williams and Wilkins; 2012: 207.

11. Schwartz SI, editor. Principles of surgery (V-2). $7^{\text {th }}$ ed. New York: McGraw-Hill; 1999: 1755-56.

12. Sadler TW. Langman's medical embryology. $11^{\text {th }}$ ed. Baltimore: Lippincott Williams and Wilkins; 2004: 240. 